Aguja de oro, dedal de plata, si la Espinel cose es muy bello coser; si la Espinel canta, el canto es como chorro de alegría; si la Espinel danza, el anhelo se siente colmado. Sublime conjuro capaz de reanimar una momia; súbita pasión quisiera lanzarse a la absurda aventura de amor, dicha infinita, furia eterna que en un instante consuma un destino y luego añoranza y olvido y llanto y misterio, ríos de llanto, entre las sombras del jardín.,

De pronto vi que la Espinel, transfigurada, recorría la América, recorría la América de uno a otro confín, renovando el alma de España en todos sus hijos de vario color de una estirpe inmortal. Sacerdotisa de España reencarnada en América desde la California perdida, hasta la Patagonia aun no ocupada. Lo que Berta Singerman para el recitado, puede llegar a ser la Espinel en la canción. Sola ella manejando, conmoviendo públicos. Alba de esperanza; clamor de victorias remotas. Deste110, fulgor.- J OS E V A S C O N E L OS.

\title{
Divagaciones alrededor de la poesía
}

\section{LA POEȘíA}

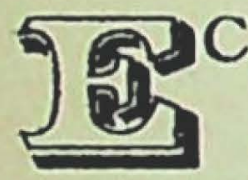

CHARSE a buscar en los libros una definición exacta de la poesía es tarea larga y seguramente inútil. Hasta ahora no se ha hecho más que divagar alrededor de la poesía, pero como toda divagación es, más o menos, una tentativa de interpretar el objeto sobre el cual se divaga, toda divagación es provechosa. Al decir poesía quiero decir sólo poesía en su esencia, en su pristinidad. No hablo de la obra poética, sino del impulso que crea la obra poética y del origen de este impulso. Tampoco me refiero a lo ingenioso, a lo razonable, a lo didáctico, a lo anecdótico, a lo social, a lo higiénico o a lo moral. La poesía, como creación pura, es independiente de todo eso.

Para definir o explicar esa poesía a que me refiero y que es la única que puede interesar a los artistas, no existe ninguna frase, ningún pensamiento decisivo. Los poetas, los sabios, los filósofos, los críticos, han escrito muchas páginas, sin lograr ponerse de acuerdo. Además existe una dificultad para interpretar el fenómeno intrínseco de la poesía: es el precon- 
cepto que cada uno tiene de ella. Esto impide enunciar una fórmula para uso de todos y cada uno de los interesados. Los poetas lo ignoran tanto como cualquiera y a veces más que cualquiera. La flauta ignora lo que es el sonido, aunque lo produzca. Si preguntamos a un poeta amigo nuestro: ¿qué es la poesía?, no sabrá qué responder o responderá vaguedades: confundirá la poesía con el arte poético o con la obra poética, y concluirá por tratar de explicarnos en qué situación intelectual o fisiológica se encontraba cuando se le ocurrió escribir tal o cual poema. Con todo esto no sacaremos nada en limpio. El instante en que el poeta siente el deseo o la necesidad de escribir un poema y el instante en que el motivo del poema surge en él, son posteriores a la aparición de la poesía en él. Este último es el que nos preocupa y éste es el que nadie ha logrado descubrir.

Casi se puede afirmar que la poesía está, por ahora, fuera del conocimiento inmediato y por encima de la inteligencia y de la voluntad directa del hombre, dentro del cual obra algunas veces como el viento en la flauta, llenándolo de su fluido sin que él lo advierta, hasta que, colmándolo, le provoca la idea poética. No queremos decir con esto que la poesía sea algo sobrenatural, no; sólo queremos decir lo que hemos dicho: que está por encima de la inteligencia inmediata y es independiente, en cierto modo, de la voluntad. No viene desde fuera del hombre: se crea dentro de él, pero sin que él sepa ni sienta cómo se crea. Si no fuera así no se comprendería cómo, después de tantos esfuerzos hechos por poetas y no poetas, no se haya llegado a una definición clara de su personalidad, que parece andar en puntillas dentro del hombre. Schiller decía:

Tout d'abord mon âme est remplie par une sorte de disposition musicale: l'idéc poétique ne vient qu'ensuite.

Disposición musical... . La idea poética no aparece sino después. . . ¿Cuándo nace esa disposición musical? ¿Cómo nace y por qué? ¿Cómo se desarrolla hasta aparecer en el poeta? Esto es la poesía en su esencia: desde que se forma hasta que nace en el hombre; lo que sigue es cosa diversa. Shelley decía:

Un poéte est un rossignol qui chante dans les ténèbres pour charmer sa propre solitude de ses doux sons; ses auditeurs sont comme hommes ravis en extase par la mélodie d'un musicien invisible, qui se sentent émus et charmés, mais qui ne savent ni d'où vient la mélodie, ni pourquoi elle les charme.

El poeta es un ruiseñor que canta en las tinieblas... . No sa- 
be de dónde viene la melodía ni por qué ella le encanta... Novalis:

Tout oeuvre d'art véritable est un symbole mystérieux qui a plusieurs significalions, et est, en un certain sens, insondable.

Observemos que el romántico alemán habla de la obra de arte $o$ del poema, o sea, del precipitado (1) de la «disposition musicale» de Schiller. Sin embargo, encuentra que tiene un sentido insondable. ¿Qué habría dicho al hablar de lo que hace surgir los poemas, de la poesía? Porque el poema, aunque en él resplandezca la poesía, no es la poesía misma, es el resultado, el fruto. Y el fruto no es el árbol ni mucho menos las raíces. ¿Dónde reside el árbol? Indudablemente, en la inteligencia, que es la resonadora. Pero, ¿y las raíces? Ahí termina el conocimiento y principia lo desconocido, lo inefable. Claro que reside también en el hombre, pero en el hombre ignorado por sí mismo. Esa es la cuestión, cuestión que día a día parece pertenecer más al cámpo de la psico-fisiología que al de la filosofía o al de la crítica literaria.

Cuando Carlyle intentaba definir la poesía como

una acción simultánea del silencio y de la palabra,

andaba lejos de la poesía, habíala dejado atrás y hablaba de la obra poética. La poesía no es acción, en el sentido corriente de la palabra, puesto que acción es el ejercicio de una potencia. La poesía, hasta el instante en que surge en el hombre, es una potencia sin ejercicio: es una vibración abstracta, sin sentido, pura, que puede morir si no encuentra terreno propicio para su desarrollo y que puede prosperar si las condiciones le son favorables.

Citemos a Rey (Psicología), procurando encontrar una explicación científica del fenómeno:

Podemos ahora emprender el estudio de las síntesis espontáneas que se forman en la conciencia entre los elementos representativos o sensaciones, gracias a su conservación, a la atención y a la asociación.... Las percepciones externas son, pues, síntesis muy complejas, en las que las sensaciones, a continuación de una serie de experiencias, y, sobre todo, las imágenes, se asocian y se fusionan conjuntamente; tanto, que una intuición inmediata acaba por reemplazar la sucesión de las operaciones múltiples que tienen realmente lugar. Hay una verdadera química mental, que no debe asombiarnos, puesto que las síntesis de este género son el procedimiento esencial de las actividades conscientes. Por ellas, una sola indicación se convierte en la equi-

(1) Entiéndase esta palabra en su significación química. 
valerte de una multitud de otras y abrevia considerablemente nuestro trabajo, economizando nuestros esfuerzos.

Esa percepción o intuición es lo que se llama comúnmente «inspiración» al hablar de arte poético o del poeta. Pero ya hemos visto el intrincado trabajo que se produce antes de la aparición de aquella intuición y que vendría a ser el origen de la poesía y la poesía misma.

Podríamos atrevernos a trazar el siguiente esquema científico: El poeta recibe las sensaciones y las absorbe sin diferenciarlas ni discernirlas de un modo inteligente, es decir, sin conocimiento de su conciencia inmediata. Las sensaciones no permanecen inactivas, no pueden permanecer inactivas desde el momento en que existe un cerebro en función, y trabajan dentro del hombre, en sus órganos; se mezclan, se cruzan, juegan, buscan sus relaciones afines, hasta que por fin encuentran su equilibrio. Algo empieza entonces a vibrar: es la poesía. El impulso de que hablamos. La vibración crece hasta resonar en la inteligencia, en la conciencia vigilante, que decía Spengler. Desde ese instante empieza lo que se podría llamar la acción exterior de la poesía, aunque esa acción no es ya la acción de la poesía: es la acción del hombre. La siente el hombre, se apodera de ella, la desarrolla según sus capacidades de desarrollo, le da la forma que puede darle, y nace entonces el poema o el verso.

Deux choses sont également requises: l'une une certaine somme de complexité, ou plus proprement de combinaison; l'autre, une certaine quantité d' esprit suggestif, quelque chose comme un courant souterrain de pensée non visible, indésini.. (Baudelaire.)

Ahora, aceptando esta generación de la poesía, podemos dividir el estado poético en tres partes:

1. Sensación.

2. Elaboración.

3. Percepción y expresión.

Examinemos estas tres partes:

1. Sensación. No hay sensaciones poéticas especiales. Cualquier sensación, intelectual o fisiológica, puede servir a la poesía. Pero además de las sensaciones afectivas y de las sensaciones de los sentidos, existen otras. Son las que se producen en el poeta sin causa exterior alguna. A éstas debe la poesía sus más altas creaciones. Son sensaciones que nacen de modo espontáneo y sin relación aparente con la razón, con el cuerpo o con los sentidos, y que se manifiestan en el poeta como simples juegos de colores, de luces, de sonidos, de imágenes, de 
frases sin significación, imposibles de atribuir a impresión alguna recibida. Son las sensaciones elaboradas por la actividad creadora:

Los factores generales que organizan nuestra vida representa:iva pueden dividirse, al parecer, en dos grupos: los factores que la organizan espontáneamente y mós o menos libremente, y los que la organizan de una manera reflexiva y sistemática. Los primeros constituyen la actividad creadora del espiritu o la imaginación; los segundos, la actividad racional, los principios directores del conocimiento. (A. Rey: Psicología.)

¿A qué sensación o a qué sensaciones se podrían atribuir estos versos?:

No son todos ruiseñores

los que cantan entre flores,

sino campanitas de plata

que tocan al alba;

sino trompeticas de oro

que hacen la salva

a los soles que adoro.

No todas las voces ledas son de sirenas con plumas, cuyas humildes espumas son las verdes alamedas, si suspendido te quedas a los süaves clamores. (Góngora.)

¿Y estos otros?:

Como cenizas, como mares poblándose, en la sumergida lentitud, en lo informe, o como se oyen desde el alto de los caminos cruzar las campanadas en cruz, teniendo ese sonido ya aparte del metal, confuso, pesando, haciéndose polvo en el mismo molino de las formas demasiado lejos o recordadas o no vistas, y el perfume de las ciruelas que rodando a tierra se pudren en el tiempo, infinitamente verdes. (Neruda.)

Estos poemas son música pura, unida a una visión «deshumanizada» de la naturaleza: creación espontánea de la imaginación creadora, creación que no debe su origen a ninguna sensàción exterior particular o que la debe a muchas sensaciones fragmentarias, que han sido, primero, elaboradas por la imaginación reproductora, cogidas luego por la creadora y vertidas al fin en la conciencia por medio de imágenes o de frases musicales. En cierto modo, se puede considerar esos poemas como obras independientes de las sensaciones exterio- 
res. $\mathrm{Y}$ al decir «en cierto modo» quiero decir que, aunque su origen intimo sea debido a sensaciones recibidas, la elaboración ha librado al poema de su influencia o representación directa, presentándolo como creación pura. Sabemos que en toda invención científica y en toda creación artística han contribuido infinitos valores recogidos de aquí y de allá, pero eso no es obstáculo para que sean consideradas como invenciones o creaciones. El hombre no puede sacar sus obras de la nada o recibirlas de un ser sobrenatural.

De muchos poemas se puede decir: «fueron escritos a raíz de recibir tal o cual sensación». Pero de otros no se puede decir nada de esto.

2. Elaboración. Para estudiar este segundo punto remitimos al lector a cualquier tratado de psicología moderna (imaginación reproductora e imaginación creadora). Su exposición sería muy larga aquí. Pero dentro de este punto hay otro: ¿Por qué en el poeta esas síntesis de sensaciones tienen una forma especial? Porque el poeta se ha creado, por la costumbre de sentir de tal manera, por el ejercicio, quizá por la voluntad, o tal vez lo posee por predisposición congénita, un ambiente espiritual particular, un molde o un órgano cerebral, donde esas sintesis deben tomar forzosamente la forma cue al poeta le conviene que tomen. Igual cosa sucede con un músico, un pintor, un escultor, o con un hombre de ciencia, con un inventor. Además, la imaginación reproductora y creadora toma parte directa en ese trabajo, elimina lo inútil, selecciona lo util y presenta al hombre lo que el hombre puede utilizar y en la forma que el poeta lo necesita. Pero en esto existen variaciones y ellas dependen del individuo y su desarrollo intelectual.

Respecto a los órganos que generan estas coordinaciones especiales, dice Rey (Psicología):

La existencia de estos centros y su mayor o menor desenvolvimiento explicarían las diferentes formas de la imaginación y las diferencias individuales. Se ha trabajado mucho en esta investigación, y la concepción más coherente es la que Flechsing ha deducido de observaciones embriológicas: -Existen, de una parte, esferas sensitivas (sensoriomotoras) que ocupan cun tercio, próximamente, de la corteza cerebral; por otra parte, centros de *asociación que ocupan los otros dos tercios.? Entre estos últimos se encontrarán centros más especialmente reservados a la coordinación imaginativa; Flechsing admite tres: el gran centro de asociación posterior (parieto-occípito-temporal); otro mucho más pequeño, anterior o frontal, y un centro medio, el más pequeño de todos (Insula de Reil). De la estructura de estos centros dependería la imaginación, su fuerza, su poder y su aspecto particular: el predominio de las regiones parietales se nota, sobre todo, en los artistas; en los sabics, el de las regiones frontales. 
3. Percepción y expresión. La percepción es lo que se llama síntesis, o sea, el resultado de la combinación de las sensaciones. Pero nosotros no queremos habiar del fenómeno de la percepción, sino de las formas que las percepciones toman en la conciencia del poeta. Estas formas son variadas y en cada artista se manifiestan de diverso modo. La forma más corriente es la imagen. La imagen es la reviviscencia de un estado de conciencia, elaborado por la actividad creadora. Al aparecer en el campo resonador del poeta, éste toma las imágenes y las expresa en palabras. La palabra es su medio de expresión, así como la nota musical es el medio de expresión del músico y el color el del pintor. Algunas veces, el poeta las expresa tal cual las recibe, en el orden que traen y sin ponerlas en relación con el razonamiento. Si el poeta sigue este procedimiento, tendremos el poema citado de Góngora, o este otro, de Cendrars:

Vida crucificada en el diario, del todo abierto, que sostengo con los brazos extendidos.

Envergadura

Cohetes

Ebullición

Gritos

Se diría un aeroplano que cae.

Soy yo.

Este es el medio de expresión de lo que se ha llamado poesía nueva o pura. Pero si el poeta sigue el otro procedimiento, el resultado será el conocido en la otra poesía, no nueva o no pura. Debemos hacer constar que las imágenes no son un patrimonio exclusivo de los poetas: aparecen en todo hombre cuyo cerebro funcione. Aparecen en los locos y en los niños, hasta en los animales. Pero cada ser hace de ellas el uso que le conviene o no hace ninguno. Esto es elemental.

Otras veces las percepciones aparecen en el poeta como una frase, como un pensamiento, como un juego de palabras, aún como una sola palabra: amor, muerte, vida, etc. En algunos casos surgen como una frase musical, que, poco a poco, se transforma en frase verbo-musical. Si las percepciones no son elaboradas luego por el raciocinio, guardan la frescura original que hemos visto en los poemas citados. Pero si el raciocinio se apodera de ellas, pierden su carácter espontáneo y aparece entonces el concepto. El concepto es la síntesis de la percepción, síntesis elaborada por la actividad representativa: es la reducción de lo múltiple a la unidad. El poeta no se expresa ya en imágenes, se expresa en conceptos, forma 
la más aceptada en la obra poética anteıior a la aparición de esta poesía.

Pero las percepciones no aparecen siempre espontáneamente en el poeta. A veces el poeta tiene que excitarlas para que aparezcan. Los que escriben versos-me refiero a los buenos versos-saben que muchas veces, al sentarse a escribir, su campo resonador está completamente vacío. Pero es necesario escribir y el poeta empieza a buscar dentro de su cerebro alguna imagen, alguna idea, alguna frase que le sirva de punto de partida. Medita, reflexiona, se abstrae, fuma, imagina un estado de conciencia, recuerda algo que le haya impresionado: una lectura, un paisaje, una mujer, cualquier cosa. (Los poetas de hoy día extraen imágenes de todas partes. Pero nuestro poeta no puede sacarlas. Le falta la fluidez de los otros.) Por fin, algo aparece:

La reflexión y la meditación son incontestablemente creadoras; la imaginación tiene allí, pues, su parte y su parte predominante, y a ella debemos en este dominio las invenciones científicas, los sistemas metafísicos, las obras de arte, las concepciones generales o especiales de la vida política, industrial y comercial. (A. Rey. Psicología.)

Esta divagación nos ha llevado más allá de lo que yo buenamente intentaba y no estoy seguro de haber expuesto mis ideas con la claridad que el tema merece. Pero una divagación es una divagación o no lo es. La mía lo es, y como cada artista tiene una divagación propia alrededor de la poesía, ésta encontrará de seguro impugnadores, rectificadores. Es fatal, pero también es útil. He intentado exponer científicamente el fenómeno poético. Feliz o desgraciadamente, la mayoría de los poetas no se conforman ni aceptan explicaciones científicas. Muchos dicen: «La poesía es un don», dando a la palabra don un significado místico. Yo no dudo que muchos poetas, grandes poetas, hayan debido o deban sus mejores creaciones al sentimiento místico que los anima o animaba, es decir, que ese sentimiento místico haya sido el creador de sus sensaciones, pero de ahí a suponer que el poeta sólo sea el transmisor de algo sobrenatural, hay mucho trecho. Teniendo como tiene el hombre un cerebro tan maravilloso, de ambos se pueden esperar grandes maravillas.

El hombre crea su don poético o posee su don poético por muchas causas: por la estructura especial de ciertos órganos cerebrales, por la delicadeza de sus sentidos y de șus sentimientos, por la predisposición orgánica e intelectual que tiene para sentir de ese modo y no de otro, por el ejercicio de esa

Atenea.-30 
predisposición, por la costumbre y por muchos otros motivos que no hay necesidad de ir a buscar fuera de él. Nada más.

Y ahora me dirá alguien:

- Ya que usted ha intentado darnos una explicación científica de la poesía, ¿por qué no nos da también una definición?

Pero, ¿para qué definición? Yo no he intentado, al escribir este artículo, buscar o crear una definición de la poesía y si empecé hablando de definición, fué porque hay que empezar de alguna manera, sobre todo cuando se trata de divagar. Una explicación me parece más útil que una definición. Además, toda definición sería literaria y peligrosa. Cierta vez le dije a un escritor, amigo mío:

- Paul Valéry dice que la poesía es una vacilación entre el sentido y el sonido.

Y él me respondió:

- De ahí a la Casa de Orates, no hay más que un paso.

Cada época literaria tiene, no diré su definición de la poesía, sino su sentido de la poesía y cada poeta de cada una de esas épocas tiene, a su vez, su sentido propio, personalísimo. Sin embargo, en cierta poesía, como en la poesía pura, por ejemplo, que no es una creación de nuestro tiempo, sino que aparece más o menos intensamente en cada época literaria, el sentido de ella se continúa sin variantes apreciables.

Tal vez en mi divagación se echen de menos ciertos matices, ciertos detalles, pero esos matices y esos detalles pertenecen más a la creación literaria de la poesía que a su fenómeno primero. De ellos procuraremos hablar en algún segundo artículo sobre la poesía y el poema.-M A N UE L R O J A S.

\section{El gregarismo en el arte}

(T) el panorama intelectual universal, y especialmente en América, subsiste la entonación polémica entre un arte humanizado y un arte deshumanizado, arte individualista contra arte societario. Diego Rivera, en México, afirmó que todo arte proletario es arte burgués. Rivera rinde tributo a la hora socializada que vive el mundo, pero quedará de él lo que haya de genérico, de humano, no la simple formalidad adscrita a un determinado intento de estética proletaria. Es comprensible, en México, la intención socializadora, de carác- 